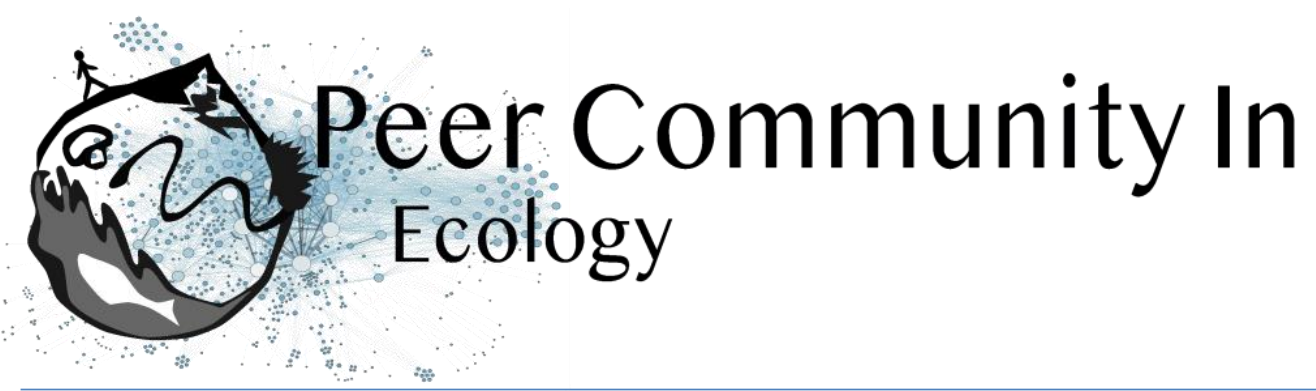

\title{
Tree diversity is associated with reduced herbivory in urban forest
}

\author{
Ruth Arabelle Hufbauer and Ian Pearse based on reviews by Freerk \\ Molleman and Ian Pearse

\section{A recommendation of:}

Alex Stemmelen, Alain Paquette, Marie-Lise Benot, Yasmine Kadiri, Hervé Jactel, Bastien Castagneyrol. Insect herbivory on urban trees: Complementary effects of tree

\section{Open Access}

neighbours and predation (2020), bioRxiv, 2020.04.15.042317, ver. 5 peer-reviewed and recommended by Peer Community in Ecology. 10.1101/2020.04.15.042317

Submitted: 20 April 2020, Recommended: 10 October 2020

Cite this recommendation as:

Published: 12 Octobre 2020

Ruth Arabelle Hufbauer and lan Pearse (2020) Tree diversity is associated with reduced herbivory in urban forest. Peer Community in Ecology, 100061. 10.24072/pci.ecology.100061

Copyright: This work is licensed under the Creative Commons Attribution-NoDerivatives 4.0 International License. To view a copy of this license, visit http://creativecommons.org/licen ses/by-nd/4.0/

Urban ecology, the study of ecological systems in our increasingly urbanized world, is crucial to planning and redesigning cities to enhance ecosystem services (Kremer et al. 2016), human health and well-being and further conservation goals (Dallimer et al. 2012). Urban trees are a crucial component of urban streets and parks that provide shade and cooling through evapotranspiration (Fung and Jim 2019), improve air quality (Lai and Kontokosta 2019), help control storm water (Johnson and Handel 2016), and conserve wildlife (Herrmann et al. 2012; de Andrade et al. 2020).

Ideally, management of urban forests strikes a balance between maintaining the health of urban trees while retaining those organisms, such as herbivores, that connect a tree to the urban ecosystem. Herbivory by arthropods can substantially affect tree growth and reproduction (Whittaker and Warrington 1985), and so understanding factors that influence herbivory in urban forests is important to effective management. At the same time, herbivorous arthropods are important as key components of urban bird diets (Airola and Greco 2019) and provide a backyard glimpse at forest ecosystems in an increasingly built environment (Pearse 2019). Maintenance of arthropod predators may be one way to retain arthropods in urban forests while keeping detrimental outbreaks of herbivores in check. In "Insect herbivory on urban trees: Complementary effects of tree neighbors and predation" Stemmelen and colleagues (Stemmelen et al. 2020) use a clever sampling design to show that insect herbivory decreases as the diversity of neighboring trees increased. By placing artificial larvae out on trees, they provide evidence that increased predation in higher diversity urban forest patches might drive patterns in herbivory. The paper also demonstrates the importance of tree species identity in determining leaf herbivory. 
The implications of this research for urban foresters is that deliberately planting diverse urban forests will help manage insect herbivores and should thus improve tree health. Potential knock-on effects could be seen for the ecosystem services provided by urban forests. While it might be tempting to simply plant more of the species that are subject to low current rates of herbivory, other research on the long-term vulnerability of monocultures to attack by specialist pathogens and herbivores (Tooker and Frank 2012) cautions against such an approach. Furthermore, the importance of urban forest insects to birds, including migrating birds, argues for managing urban forests more holistically (Greco and Airola 2018).

Stemmelen et al. (2020) used an observational approach focused on urban forests in Montreal, Canada in their research. Their findings suggest follow-up research focused on a broader cross-section of urban forests across latitudes, as well as experimental research. Experiments could, for example, exclude avian predators with netting (e.g. (Marquis and Whelan 1994)) to evaluate the relative importance of birds to managing urban insects on trees, as well as the flip side of that equation, the important to birds of insects on urban trees.

In summary, Stemmelen and colleague's manuscript illustrates clever sampling and use of observational data to infer broader ecological patterns. It is worth reading to better understand the role of diversity in driving plant-insect community interactions and given the implications of the findings for sustainable long-term management of urban forests.

\section{References}

Airola, D. and Greco, S. (2019). Birds and oaks in California's urban forest. Int. Oaks, 30, $109-116$. de Andrade, A.C., Medeiros, S. and Chiarello, A.G. (2020). City sloths and marmosets in Atlantic forest fragments with contrasting levels of anthropogenic disturbance. Mammal Res., 65, 481-491. doi: https://doi.org/10.1007/s13364-020-00492-0

Dallimer, M., Irvine, K.N., Skinner, A.M.J., Davies, Z.G., Rouquette, J.R., Maltby, L.L., et al. (2012). Biodiversity and the Feel-Good Factor: Understanding Associations between Self-Reported Human Well-being and Species Richness. Bioscience, 62, 47-55. doi: https://doi.org/10.1525/bio.2012.62.1.9 Fung, C.K.W. and Jim, C.Y. (2019). Microclimatic resilience of subtropical woodlands and urban-forest benefits. Urban For. Urban Green., 42, 100-112. doi: https://doi.org/10.1016/j.ufug.2019.05.014 Greco, S.E. and Airola, D.A. (2018). The importance of native valley oaks (Quercus lobata) as stopover habitat for migratory songbirds in urban Sacramento, California, USA. Urban For. Urban Green., 29, 303-311. doi: https://doi.org/10.1016/j.ufug.2018.01.005

Herrmann, D.L., Pearse, I.S. and Baty, J.H. (2012). Drivers of specialist herbivore diversity across 10 cities. Landsc. Urban Plan., 108, 123-130. doi: https://doi.org/10.1016/j.landurbplan.2012.08.007 Johnson, L.R. and Handel, S.N. (2016). Restoration treatments in urban park forests drive long-term changes in vegetation trajectories. Ecol. Appl., 26, 940-956. doi: https://doi.org/10.1890/14-2063 Kremer, P., Hamstead, Z., Haase, D., McPhearson, T., Frantzeskaki, N., Andersson, E., et al. (2016). Key insights for the future of urban ecosystem services research. Ecol. Soc., 21: 29. doi: http://doi.org/10.5751/ES-08445-210229

Lai, Y. and Kontokosta, C.E. (2019). The impact of urban street tree species on air quality and respiratory illness: A spatial analysis of large-scale, high-resolution urban data. Heal. Place, 56, 80-87. doi: https://doi.org/10.1016/j.healthplace.2019.01.016

Marquis, R.J. and Whelan, C.J. (1994). Insectivorous birds increase growth of white oak through consumption of leaf-chewing insects. Ecology, 75, 2007-2014. doi: https://doi.org/10.2307/1941605 Pearse, I.S. (2019). Insect herbivores on urban native oak trees. Int. Oaks, 30, 101-108. Stemmelen, A., Paquette, A., Benot, M.-L., Kadiri, Y., Jactel, H. and Castagneyrol, B. (2020) Insect herbivory on urban trees: Complementary effects of tree neighbours and predation. bioRxiv, 2020.04.15.042317, ver. 5 peer-reviewed and recommended by PCl Ecology. doi: https://doi.org/10.1101/2020.04.15.042317 Tooker, J. F., and Frank, S. D. (2012). Genotypically diverse cultivar mixtures for insect pest management and increased crop yields. J. Appl. Ecol., 49(5), 974-985. doi: https://doi.org/10.1111/j.1365-2664.2012.02173.x Whittaker, J.B. and Warrington, S. (1985). An experimental field study of different levels of insect herbivory 


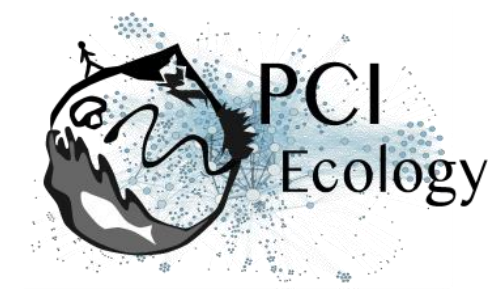

induced By Formica rufa predation on Sycamore (Acer pseudoplatanus) III. Effects on Tree Growth. J. Appl. Ecol., 22, 797. doi: https://doi.org/10.2307/2403230

\section{Revision round \#2}

\section{0-09-06}

Dear Drs. Castagneyrol and Paquette,

Thank you for carefully addressing the reviewers comments. I find your manuscript much improved. I have read the manuscript in MS word, and took the liberty of making suggested edits using track changes, and commenting using the comment tool.

My suggestions are quite minor and I hope you will find them helpful and will submit a finalized pre-print at your convenience. I would like to write a recommendation focused on how much can be revealed from this kind of work, what it suggests would be a next step, and the implications for urban forest management.

Hmm. I'm getting an error message when I attaching the file. I'm going to remove it from this email going through $\mathrm{PCl}$ Ecology, and will send a separate email outside the system with the file attached.

With my best wishes, Ruth

\section{Preprint DOI: https://doi.org/10.1101/2020.04.15.042317}

\section{Author's reply:}

Dear PCl Ecology team,

We thank you again for this second round of review of our manuscript "INSECT HERBIVORY ON URBAN TREES: COMPLEMENTARY EFFECTS OF TREE NEIGHBOURS AND PREDATION" and we return to you a revised and improved version.

As the suggestions were quite minor and we fully agreed with them, we didn't write a full response describing each changed we made, but we took into account each requested edits and marked the change in blue in the text.

If there is any problem, let us know! Sincerely yours,

Alex Stemmelen

\section{Revision round \#1}

2020-05-27

Dear authors,

The reviewers and I appreciate the work you present. However, to warrant recommendation by PCI Ecology a fairly major revision should be implemented, following the suggestions of the reviewers, including exploring new analyses as suggested by the reviewers, and making sure that the title appropriately describes the results.

As with a traditional journal, a detailed response to reviews would be appreciated upon resubmission. Best wishes, 
Ruth Hufbauer, Professor

Additional requirements of the managing board:

As indicated in the 'How does it work?' section and in the code of conduct, please make sure that: -Data are available to readers, either in the text or through an open data repository such as Zenodo (free), Dryad or some other institutional repository. Data must be reusable, thus metadata or accompanying text must carefully describe the data. -Details on quantitative analyses (e.g., data treatment and statistical scripts in R, bioinformatic pipeline scripts, etc.) and details concerning simulations (scripts, codes) are available to readers in the text, as appendices, or through an open data repository, such as Zenodo, Dryad or some other institutional repository. The scripts or codes must be carefully described so that they can be reused. -Details on experimental procedures are available to readers in the text or as appendices. -Authors have no financial conflict of interest relating to the article. The article must contain a "Conflict of interest disclosure" paragraph before the reference section containing this sentence: "The authors of this preprint declare that they have no financial conflict of interest with the content of this article." If appropriate, this disclosure may be completed by a sentence indicating that some of the authors are $\mathrm{PCl}$ recommenders: "XXX is one of the $\mathrm{PCI}$ XXX recommenders."

Preprint DOI: $\underline{\text { https://doi.org/10.1101/2020.04.15.042317 }}$

\section{Reviewed by Ian Pearse, 2020-05-08 22:48}

This is an interesting urban ecology paper about rates of herbivory and predation of herbivores on urban trees in parks in Montreal. The study finds that herbivory is associated with some combination of tree diversity (negatively) and density (positively), and that predation rate has roughly the opposite association. The findings of the study are a bit limited by the strong correlation between tree density and diversity. The writing is good, and the results are discussed with a thorough background of urban plant-insect literature. Because the study considers resource concentration, it would be a nice additional analysis to look at the density of conspecifics around a focal tree. Overall, I think this manuscript can be a nice addition to the urban herbivory literature.

L60: Perhaps 'study', as 'experiment' tends to imply manipulations of some sort, which is not the case here. L90: What predatory arthropods attack these models? This would seem like quite a feat (and act of deception), and I am surprised that this happens. Do mammals, rodents, etc, attack the models? 107: whom $>$ who

L120 This also means that you cannot really interpret results based on one or the other of these factors (because you are explicitly saying that they measure the same thing), which is currently done in the discussion and abstract, which attributes herbivory to tree diversity and attack rates to tree density. With only 5 tree species, it is unclear whether including it as a random effect (RE) makes more sense than a fixed effect. The typical cutoff is more like 15 in order to estimate variance of a RE. It probably makes little difference for the analysis though, as tree species seems to explain little variance anyhow. In the intro, the resource concentration hypothesis is introduced. I think it could make sense to analyze the data with reference to the density of the same tree species within the neighborhood of the focal tree. (i.e. how many sugar maples were near to a focal sugar maple). We do not really know the host breadth of insects causing damage in this study (or the feeding tendency of birds with reference to tree species), but it seems reasonable to think of the same tree species as a 'host' for an individual herbivore. There is some evidence for an effect of density of conspecifics in urban settings, such as with gall wasp diversity (Herrmann et al 2012 Landscape and Urban Planning), although that study was with some really specialized herbivores. 
I might recommend presenting the herbivory results before the predation rates results. The predation results are more interesting in general, but I think they become even more interesting when we see that herbivory varies in predictable ways.

L177: The problem is that you say that you show in the methods that you cannot distinguish between these two things.

L187 and elsewhere. don't need Hervé's first name or initial.

What is the evidence for how birds feed on herbivores of differing densities? This would be an alternate explanation to the causal predation -> (-) herbivory link. It could be that herbivore density -> (-) predators if birds are, say territorial and attack a lower percentage of herbivores when those herbivores are abundant. Is there any consensus as to how birds feed based on prey density? It is interesting that there is little effect of tree identity in the study, particularly considering that tree architecture (Nell and Mooney studies) and defenses (Singer and Mooney studies) can modulate attack rates of caterpillars by birds.

\section{Reviewed by Freerk Molleman, 2020-05-21 15:44}

This is a useful contribution to the field. Especially the inclusion of predation data makes the study interesting. I am more interested in the community ecology than in the urban application. The abstract starts with a long introduction about urban trees, while the introduction starts with the basic science to then go to urban trees, and the discussion doesn't deal with things that are different in urban environment such as pollution and temperature. Why would there be a difference between abstract and introduction (intro approach better for me), and why would natural systems differ from urban one's? This is not explained. May be you can point out that parks and other urban trees are almost all planted so they are like common garden experiments ready for use by biologists. Notably, tree density is often low in parks. Then of course there is also a practical interest, but I doubt such considerations will often be used in urban planning and park design.

The study found that higher tree density was correlated with higher predation rates. This was the most clearcut effect, but did not make it to the title. High tree diversity and higher predation rates both correlated with less leaf damage. Perhaps there is a mechanistic link that higher tree diversity increases predation rate which decreases herbivory. Collinearity may be avoided by using residuals to tease this apart further?

The title suggests that the study is about the neighbouring trees, but in fact it is about diversity in a $20 \mathrm{~m}$ radius. This is a different matter. The finding may not be conclusive, but it is tantalizing. I suggest a further analysis. Identity of neighbouring trees may be important, especially the \% of neighbouring trees that are of same species or of closely related species (congeners). Other studies have looked at neighbourhoods in this way. With this analysis, the title would become true. The authors made a methodological mistake that is not fatal, but does need to be mentioned in the discussion. It is wrong to expose dummies at the same spot for extended periods of time. Birds can quickly learn to avoid dummies this way. If dummies were observed intermittently, a decrease in attack rate over time would probably be evident. It is still possible to compare among trees in this set-up. The seasonal part is more difficult to interpret quantitatively.

Sample sizes are a bit small when only 1-2 trees per species is/are used for one of the parks, but mostly it should be fine.

Denser tree cover also means more concentrated resources (insects) for insectivores. An expectable functional response seem to happen here: higher predation rate when trees are planted more densely. A similar functional response may explain predation rate in spring vs summer. Please look for other dummy studies that use longer time spans. Was there an effect of tree species on predation rate? Species with more leaf damage may get higher predation rates. Please strengthen the discussion on these points. 


\section{in 2 . Pcology}

Line 107: So leaves were photographs, scanned, collected for later assessment of damage? Instead of 'target tree' I would use 'focal tree'.

\section{Author's reply:}

Download author's reply (PDF file) 